\title{
UNINTENTIONAL POISONING IN THE WEST
}

0 ne of the goals of the Better Health Commission is 'to increase protection against and reduce exposure to environmental hazards posing a threat to health'. By the year 2000 it is hoped to reduce by 10 per cent deaths and injuries caused at home by hazardous chemicals. With this in mind the Western Sector Public Health Unit decided to review some aspects of unintentional poisonings in its area.

This report summarises the separations in $1988-89$ as a result of unintentional poisoning in the Western Sydney Area Health Service (WSAHS) and the Wentworth Area Health Service (WAHS). Poisonings as acts of attempted suicide are not included.

Information was obtained for all separations in the $\mathrm{E}$ code categories E850-E858 and E860-869 (International Classification of Diseases, Ninth Edition). The E code allows the classification of environmental events, circumstances and conditions as the cause of injury, poisoning, and other adverse effects.

Unintentional poisoning by drugs, medicinal substances and biologicals (E850-E858) include unintentional overdose of drug, wrong drug given or taken in error, and a drug taken inadvertently. These substances were grouped together for the purposes of analysis.
The $\mathrm{E}$ codes $860-869$ include unintentional poisoning by other solid and liquid substances, gases and vapours. Appendix 1 lists the relevant $\mathrm{E}$ codes.

For each separation, information was obtained on age, sex, place of occurrence, number of bed days and average length of stay. The data were obtained from the Information Services Branch of the NSW Health Department.

Overall, in WSAHS and WAHS in 1988-89, total separations because of unintentional poisonings accounted for about 7 per cent of all separations due to accidents and injuries (WSAHS: $n=711$; WAHS: $n=347$ ). Separations by E code, age-group, sex and place of occurrence were similar for the two health areas.

Just over 85 per cent of all unintentional poisonings were from drugs and medicinal substances (Figure 1), the majority of which were prescription drugs. Anti-rheumatics, analgesics, antipyretics and the tranquillisers were the most commonly implicated drugs. Other classes of substances were each implicated in only 2-3 per cent, or fewer, of all separations due to unintentional poisoning.

The majority of the poisonings occurred in the 15- to 34-year group, with a smaller peak in the 1- to 4-year

\section{FIGURE 1}

UNINTENTIONAL POISONING 1988/89 SEPARATION BY E CODE

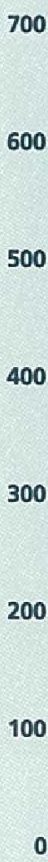

n

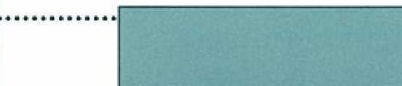

.............

...................

...............
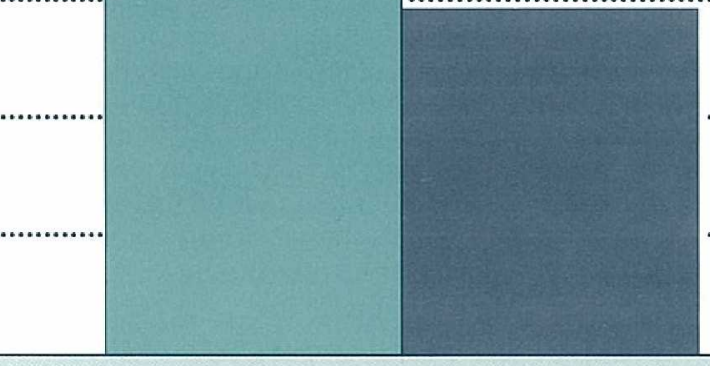

850

$860-869$

E Code

WSAHS
WSAHS - WESTERN SYDNEY AREA HEALTH SERVICE

WAHS - WENTWORTH AREA HEALTH SERVICE 


\section{APPENDIX 1}

CATEGORIES OF E CODES

8500-8589 Unintentional poisoning by drugs, medicinal substances and biologicals

8600-8609 Unintentional poisoning by alcohol, not elsewhere classified

8610-8619 Unintentional poisoning by cleansing and polishing agents, disinfectants, paints and varnishes

8620-8629 Unintentional poisoning by petroleum products, other solvents and their vapours, not elsewhere classified

8630-8639 Unintentional poisoning by agricultural and horticultural chemical and pharmaceutical preparations other than plant food and fertilizers

8640-8644 Unintentional poisoning by corrosives and caustics, not elsewhere classified

8650-8659 Unintentional poisoning from foodstuffs and poisonous plants

8660-8669 Unintentional poisoning by other and unspecified solid and liquid substances

867 Unintentional poisoning by gas distributed by pipeline

8680-8689 Unintentional poisoning by other utility gas and other carbon monoxide

8690-8699 Unintentional poisoning by other gas and vapours

group. There were more females than males (females: 57 per cent; males: 43 per cent), and females outnumbered males in most of the age groups except for children aged 9 and less.

In WSAHS, 52 per cent of the unintentional poisonings occurred in the home while it was 47 per cent in WAHS. In a fairly large proportion of cases the place of occurrence was not specified (WSAHS: 26 per cent; WAHS: 47 per cent).

The average length of stay generally increased with age. In WSAHS, males had longer average stays than females (males: 2.9 days; females: 2.5 days). It was the opposite in WAHS (females: 2.6 days; males: 1.5 days).

From the data reviewed it appears the emphasis on the prevention of unintentional poisoning should be directed toward the area of drugs and medicinal substances.

Since the majority of poisonings occur at home, it would also be important to take this into account when planning prevention strategies.

It is intriguing that in both the health areas, the 15to 24- and the 25- to 34-year groups have the highest number of separations due to drugs and medicinal substances. This is due to coding practices whereby some non-unintentional poisonings, such as attempted suicides, are coded as unintentional if certain criteria are met.

In both the health areas, separations due to accidental poisoning rank fifth in terms of total separations for all external causes (6-7 per cent). The vast majority of the unintentional poisonings are by drugs and medicinal substances, and in the most part occur in the home. se of gamma benzene hexachloride (Lindane) for the treatment of head lice has been under discussion, but the director of the NSW Health Department's Toxicology Unit, Dr David Fox, has given an assurance that if used as intended the preparation is safe. He has sent this letter to all health areas and regions:

"The use of gamma benzene hexachloride (Lindane) for the treatment of head lice has been questioned.

The two main preparations used for this purpose have been Quellada and Lorexane and both are listed in Schedule 2 of the Poisons Act. This limits the concentration of Lindane to 2 per cent or less and its sale for the treatment of head lice is restricted to pharmacists and medical practitioners. It may also be sold by Poisons Licence holders, namely retail stores at least $20 \mathrm{~km}$ from the nearest pharmacy.

Preparations of greater strength are Schedule 4 items, available only on doctor's prescription.

Quellada contains 1 per cent Lindane and Lorexane 0.2 per cent. For each preparation the recommended dose is $25 \mathrm{ml}$ per treatment. Repeat treatment in eight days is recommended for Lorexane. A second application of Quellada is said to be seldom required.

The use of Lindane was discussed recently at the Drugs and Poisons Scheduling Committee of the National Health and Medical Research Council (NH\&MRC), which recommended retention of Lindane in Schedule 2.

A recent communication from the NH\&MRC stated that absorption of Lindane through human skin is reported to be a maximum of 9.3 per cent of the applied dose and that there is little danger of accumulation as it has properties dissimilar to some other persistent organochlorines.

The NH\&MRC also informs that published information on animal studies shows that Lindane is extensively metabolised and rapidly excreted. Even when fed continuously it does not significantly accumulate in the body.

It was also indicated that most purchasers of head lice products seek advice from pharmacists who do not recommend prophylactic use.

Most therapeutic agents have the potential to cause adverse effects if abused, and misuse is difficult to regulate. Lindane is no exception, but used as intended for head lice, it is safe." 